\title{
ИСПОЛЬЗОВАНИЕ ИМПУЛЬСНОГО ЛАЗЕРНОГО ИК-ИЗЛУЧЕНИЯ С ДЛИНОЙ ВОЛНЫ 1,06 МКМ ДЛЯ ФОРМИРОВАНИЯ СПЕЦИАЛЬНОЙ МИКРОСТРУКТУРЫ В ХРЯЩЕВОЙ ТКАНИ
}

\author{
А.С. Шах ${ }^{1}$, Е.И. Исаев ${ }^{1}$, Д.С. Барановский ${ }^{2,3}$, Г.А. Демяшкин ${ }^{4}$, И.Д. Клабуков ${ }^{5}$ \\ ${ }^{1}$ Отделение института лазерных и плазменных технологий, Обнинский институт атомной энергетики - \\ филиал федерального государственного автономного образовательного учреждения высшего образования \\ «Национальный исследовательский ядерный университет «МИФИ», тер. Студгородок, 1, Обнинск, \\ Российская Федерация, 249040 \\ E-mail: shakhlina2@gmail.com, e.isaev87@gmail.com \\ ${ }^{2}$ Отделение лучевого и хирургического методов лечения заболеваний торакальной области МРНЦ им. \\ А.Ф. Цыба - филиала ФГБУ «НМИЦ радиологии» Минздрава России, ул. Королева, 4, Обнинск, Российская \\ Федерация, 249036 \\ ${ }^{3}$ Научно-образовательный ресурсный центр «Клеточные технологии» РУДН. ул. Миклухо-Маклая, 6, \\ Москва, Россия, 117198 \\ E-mail: doc.baranovsky@gmail.com \\ ${ }^{4}$ Лаборатория радиационной патоморфологии МРНЦ им. А.Ф. Цыба - филиала ФГБУ «НМИЦ радиологии» \\ Минздрава России, ул. Королёва, 4, Обнинск, Российская Федерация, 249036 \\ E-mail:dr.dga@mail.ru \\ ${ }^{5}$ Отделение регенеративных технологий и биофабрикации ФГБУ «НМИЦ радиологии» Минздрава России, \\ ул. Королева, 4, Обнинск, Российская Федерация, 249036 \\ E-mail: ilya.klabukov@gmail.com
}

Использование лазерного излучения для диагностики и лечения находит широкое применение в реконструктивной хирургии. Однако в последние годы получила развитие новая область применения лазерного излучения - тканевая инженерия. В настоящей работе исследовалась возможность использования лазерного инфракрасного излучения длиной волны $\lambda=1,06$ мкм для создания матриксов для тканеинженерных конструкций. В работе показана возможсность использования лазерного излучения с $\lambda=1,06$ мкм для создания имплантатов на основе хрящевой ткани ушной раковины кролика. Лазерная перфорация доказала свою эффективность для микроструктурной модификации поверхности ушного хряща кролика. Формирование микроструктуры, которую в последующем можсно использовать в качестве тканеинженерной конструкции, происходит в результате индуцирвания неоднородного температурного поля вследствие нерезонансных оптических потерь из-за рассеяния на компонентах биоткани с масштабом 1-5 мкм.

Ключевые слова: лазерная перфорация, модификация хрящевой ткани, оптические характеристики биотканей, воздействие лазерного излучения на биоткань

\section{THE USE OF PULSED LASER INFRARED RADIATION WITH A WAVELENGTH OF 1.06 MM FOR THE FORMATION OF A SPECIAL MICROSTRUCTURE IN CARTILAGINOUS TISSUE}

\footnotetext{
A.S. Shakh ${ }^{1}$, E.I. Isaev ${ }^{1}$, D.S. Baranovsky ${ }^{2,3}$, G.A. Demyashkin ${ }^{4}$, I.D. Klabukov ${ }^{5}$

${ }^{1}$ Institute for laser and plasma technologies, Obninsk Institute for Nuclear Power Engineering, Studgorodok, 1, Obninsk, Russian Federation, 249040

E-mail: shakhlina2@gmail.com, e.isaev87@gmail.com

${ }^{2}$ Department of Radiation and Surgical Methods of Treatment of Thoracic Diseases, Federal State Budgetary Institution "National Medical Research Center of Radiology" of the Ministry of Health of Russian Federation, Koroleva St. 4, Obninsk, Russian Federation, 249036
} 
${ }^{3}$ Scientific and Educational Resource Center "Cellular Technologies" RUDN. Miklukho-Maklaya st., 6, Moscow, Russian Federation, 117198

E-mail: doc.baranovsky@gmail.com

${ }^{4}$ Laboratory of Radiation Pathomorphology, A. Tsyb Medical Radiological Research Centre - branch of the National Medical Research Radiological Centre of the Ministry of Health of the Russian Federation, Koroleva St. 4, Obninsk, Russian Federation, 249036

E-mail: dr.dga@mail.ru

${ }^{5}$ Department of Regenerative technologies and Biofabrication, National Medical Research Radiological Centre of the Ministry of Health of the Russian Federation, Koroleva St. 4, Obninsk, Russian Federation, 249036

E-mail: ilya.klabukov@gmail.com

Laser radiation is widely used for diagnostics and treatment in reconstructive surgery. However, recent years opened new area for further implication of laser perforation - tissue engineering. In this study, we investigated the capability of laser infrared radiation with a wavelength of $\lambda=1,06 \mu \mathrm{m}$ to create matrices for tissue-engineered grafts. Laser perforation was shown to be an effective tool for superficial microstructural modification of rabbit auricle cartilage. The formation of a microstructure was induced by an inhomogeneous temperature field of nonresonant optical losses due to scattering on biological tissue components with a scale of 1-5 $\mu \mathrm{m}$.

Key words: laser perforation, cartilage modification, optical properties of biological tissues, the effect of laser radiation on biological tissue

Для цитирования:

Шах А.С., Исаев Е.И., Барановский Д.С., Демяшкин Г.А., Клабуков И.Д. Использование импульсного лазерного ИК-излучения с длиной волны 1,06 мкм для формирования специальной микроструктуры в хрящевой ткани. Рос. хим. ж. (Ж. Рос. хим. об-ва). 2021. T. LXV. № 3. С. 62-66

For citation:

Shakh A.S., Isaev E.I., Baranovsky D.S., Demyashkin G.A., Klabukov I.D. The use of pulsed laser infrared radiation with a wavelength of $1.06 \mu \mathrm{m}$ for the formation of a special microstructure in cartilaginous tissue. Ros. Khim. Zh. 2021. V. 65. N 3. P. $62-66$

\section{ВВЕДЕНИЕ}

В настоящее время к исследованиям процессов лазерного воздействия на различные биологические ткани сохраняется большой интерес. Это связано с широким применением лазеров в отоларингологии, стоматологии, хирургии и других областях медицины.

Кадаверная хрящевая ткань может служить матриксом-носителем для изготовления различных биоимплантатов. В частности, исследованы возможности создания тканеинженерных конструкций на основе кадаверной хрящевой ткани для закрытия протяженных дефектов трахеи возникающих в процессе хирургического лечения стенозов и опухолевых процессов. При этом лазерное воздействие на хрящевую ткань применяется в медицинских технологиях для изменения формы хрящевой ткани, модификации ее поверхности с целью формирования условий для ревитализации - активного заселения матрикса-носителя клетками и активации процессов регенерации хряща [1].

Использование низкоинтенсивного ИК-лазерного излучения позволяет проводить сквозную перфорацию, а также создавать «слепые» (несквозные) лунки в хрящевой ткани, увеличивая ее удельную поверхность для фиксации хондроцитов. Вследствие такой модификации увеличивается удельная поверхность, на которой происходит закрепление материала, повышается биодоступность объема материала и стимулируется миграция заселяемых клеток [2].

На сегодняшний день, использование лазерного воздействия является новейшим и эффективным методом подготовки матриксов-носителей на основе плотных хрящевых тканей к витализации [2]. В рамках данной работы проводился подбор параметров лазерного излучения $(\lambda=1,06$ мкм), при котором в хрящевой ткани ушной раковины кролика сформировалась особая микроструктура, необходимая при создании тканеинженерной конструкции.

\section{МЕТОДИКА И РЕЗУЛЬТАТЫ ЭКСПЕРИМЕНТА}

В качестве материала для получения бесклеточного матрикса-носителя применяли образцы хрящевой ткани ушной раковины кроликов-доноров породы «Серый великан». Образцы нативной 
ткани для исследований были предоставлены ФГБУ «НМИЦ Радиологии» Минздрава России.

Хрящевая ткань подвергалась девитализации методом пятикратного повторения циклов глубокой заморозки до $-195,75^{\circ} \mathrm{C}$ и оттаивания при $37{ }^{\circ} \mathrm{C}$. Девитализированная ткань хранилась при температуре $4{ }^{\circ} \mathrm{C}$ в физиологическом растворе с добавлением антибиотика Пенициллин-Стрептомицин $1 \%$ во избежание пересыхания и загрязнения. Перед выполнением лазерной перфорации проводилось отмывание образцов в холодном физиологическом растворе в течении 30-60 мин. в верхнеприводной мешалке. Затем готовый образец закреплялся на влажной губке, для того, чтобы во время лазерной перфорации не происходило грубой деформации поверхности в процессе локального нагрева.

Хрящевая ткань ушной раковины кролика для создания тканеинженерной конструкции подвергалась воздействию лазерного излучения с длиной волны 1,06 мкм при различных параметрах облучения. Перфорация выполнялась при постоянном смачивании хрящевой ткани водой с целью предотвращения локального перегрева биоткани и последующего ее обугливания. В качестве параметров микроструктуры были выбраны следующие: диаметр «слепых» (несквозных) лунок - 150 мкм, расстояние между лунками - 250 мкм, глубина - 200300 мкм.

Морфология поверхности изучалась методами оптической микроскопии (металлографический микроскоп МЕТАЛЛ ЛВ-41) и сканирующей электронной микроскопии (Nova NanoSEM 230). На рис. 1 и 2 приведены результаты воздействия лазерного излучения на хрящевую ткань ушной раковины.

Для оценки глубины перфорации было проведено гистологическое исследование всех образцов нативных тканей. Гистологическое исследование матриксов-носителей выполнялось после предварительного выдерживания образцов в растворе формальдегида $4 \%$ в течение 4 часов и парафинизации. Для гистологического исследования образцов с парафиновых блоков получали срезы толщиной 20 мкм с использованием микротомов (Thermo Fisher Scientific, США). Полученные срезы депарафинизировали, окрашивали гематоксилином и эозином, дегидратировали и просветляли в ксилоле. Микроскопия и цифровые микрофотографии для морфологического исследования выполнялись с помощью светового микроскопа Nikon Eclipse L200 и автоматической установки Pannoramic DESK. Результаты гистологического исследования приведены на рис. 3.

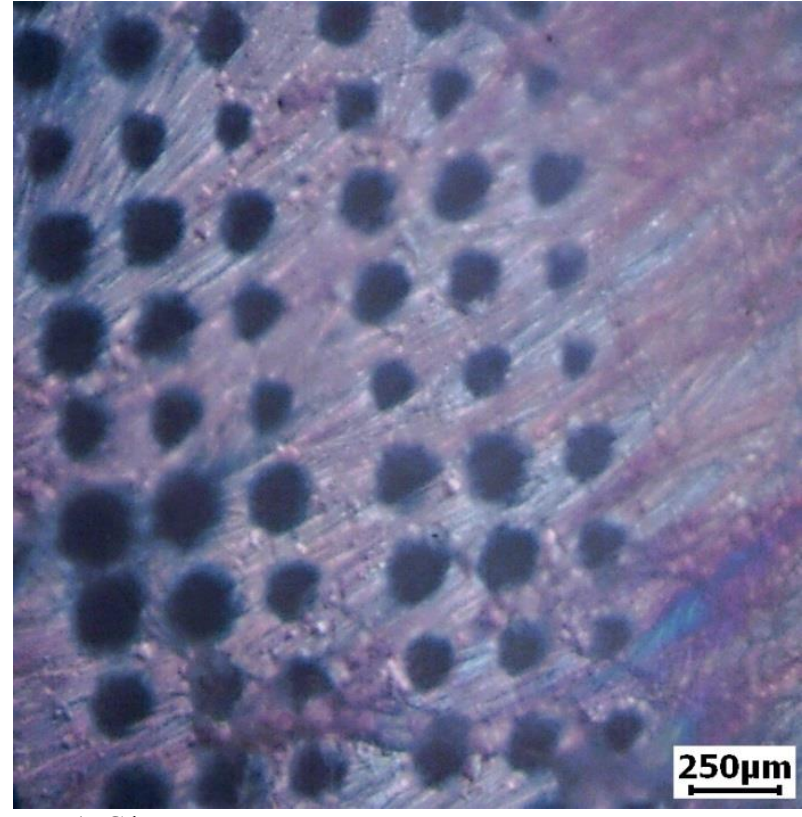

Рис. 1. Сформированные «слепые» лунки в хрящевой ткани ушной раковины кролика поляризованный свет

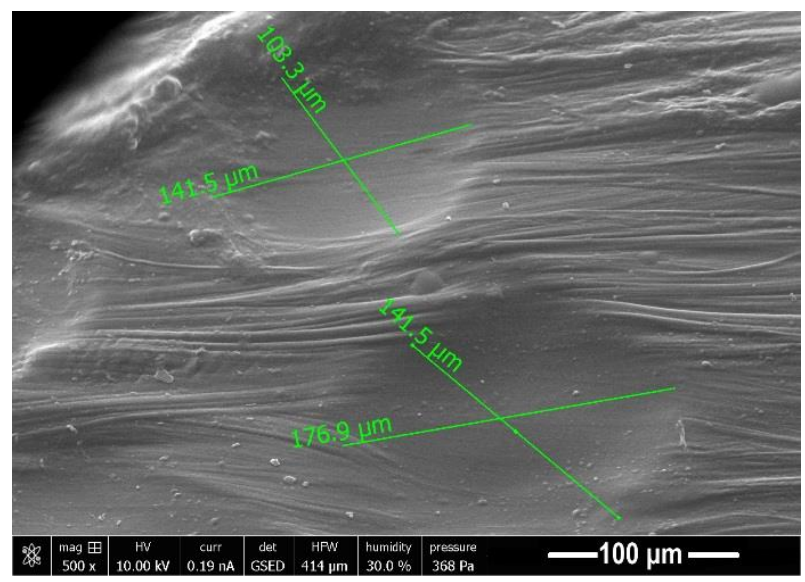

Рис. 2. Электронномикроскопическое изображение «слепых» лунок, полученных после лазерной перфорации

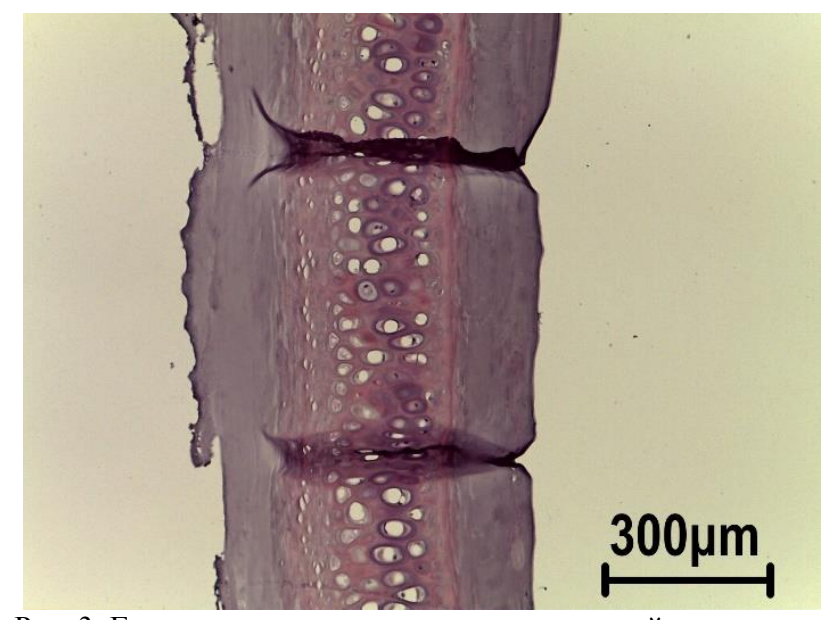

Рис. 3. Гистологическое исследование хрящевой ткани после лазерной перфорации

окраска гематоксилин-эозин 
На изображениях микроструктуры хрящевой ткани после лазерной перфорации, приведенных на рис. 1 и 2 можно видеть, что на поверхности биоткани сформировалась специальная микроструктура. Согласно результатам оптической и электронной микроскопии, диаметр «слепых» лунок составляет 100-160 мкм, что можно считать удовлетворительным результатом, расстояние между лунками составляет 220-270 мкм.

\section{ОБСУЖДЕНИЕ РЕЗУЛЬТАТОВ}

В результате того, что хрящевая ткань представляет собой сложную неоднородную систему, состоящую из твердой матрицы и межтканевой жидкости, то при попадании излучения на поверхность происходят процессы рассеяния, поглощения [3]. Рассеяние излучения в биоткани происходит вследствие того, что структура биологической ткани имеет негомогенный характер, ячеистую структуру и определяется наличием границ между разных ячеек и окружающей их среды. Рассеяние в биологической ткани, когда размер оптических неоднородностей много меньше длины волны падающего излучения, описывается теорией Рэлея [4]. Оптические потери на рассеяние в этом случае описываются:

$$
\begin{aligned}
& \alpha=n_{d}\left(n_{e} r_{e} d^{3}\right)^{2} \frac{\lambda_{o}^{4}}{\left(\lambda^{2}-\lambda_{o}^{2}\right)^{2}} \\
& n_{d}=\frac{1}{d^{3}} \\
& n_{e}=\frac{\rho \cdot N_{a}}{M}
\end{aligned}
$$

где $\alpha$ - показатель поглощения, $n_{d}-$ концентрация оптических неоднородностей в объеме материала, $n_{e}-$ концентрация валентных электронов, $r_{e}-$ классический радиус электрона, $d$ - средний размер оптических неоднородностей, $\lambda_{0}-$ длина волны, соответствующая ширине запрещенной зоны материала.

Подставляя уравнения (2) и (3) в уравнение (1), можно получить следующее выражение:

$$
\begin{aligned}
\alpha=d^{3}\left(\frac{r_{e} \cdot \rho \cdot N_{a}}{M}\right)^{2} \cdot f(\lambda), \\
\text { где } \quad f(\lambda)=\frac{\lambda_{o}^{4}}{\left(\lambda^{2}-\lambda_{o}^{2}\right)^{2}} .
\end{aligned}
$$

В результате многократного рассеяния лазерного излучения на границах оптических неоднородностей хрящевой ткани области с большим показателем поглощения перегреваются относительно областей, имеющих меньший показатель поглощения. Это приводит к образованию неоднородного температурного поля и возникновению различных физических процессов, которые являются причиной появления «слепых» лунок (рис. 3). В этом заключается отличие влияния нерезонансно и резонансно поглощаемого излучения.
Например, в среднем ИК диапазоне поглощение излучения определяется в основном поглощением воды. В лазерной хирургии, где в основном используется $\mathrm{CO}_{2}$ лазер с длиной волны 10,6 мкм, нагрев осуществляется однородно во всем слое облучаемой биоткани. Излучение в ближнем ИК диапазоне практически не поглощается водой $\left(\alpha<1 \mathrm{~cm}^{-1}\right)$, также слабо поглощается остальными тканевыми компонентами, проникает в результате многократного рассеяния на глубину в несколько миллиметров и приводит к неоднородному нагреву или к неодинаковому вследствие различного поведения с повышением температуры различных компонентов ткани. Спектр оптических потерь в хрящевой ткани ушной раковины кролика показан на рисунке 4 (черная кривая). Спектр пропускания хрящевой ткани был получен с помощью однолучевого спектрометра UVmini-1240 в интервале длин волн 4001100 нм.

В соответствии с законом Бугера был определен показатель поглощения хрящевой ткани:

$$
\alpha=\frac{\ln T}{l},
$$

где $T$ - пропускание, $l$ - длина оптического пути (толщина образца). Оценка, выполненная с использованием теории рассеяния Рэлея, дает значения размеров оптических неоднородностей 1-5 мкм, что сопоставимо с размерами элементов структуры хрящевой ткани [5]. Также были рассчитаны теоретические спектры оптических потерь в биоткани с помощью уравнения (4). Результат расчетов приведен на рисунке 4 в виде заштрихованной области вверх и вниз от экспериментально полученного спектра. Стоит отметить, что такая оценка является очень приблизительной, т.к. для рассеяния Рэлея необходимо, чтобы $d \ll \lambda$ и для более точного расчета следует использовать теорию рассеяния Ми.

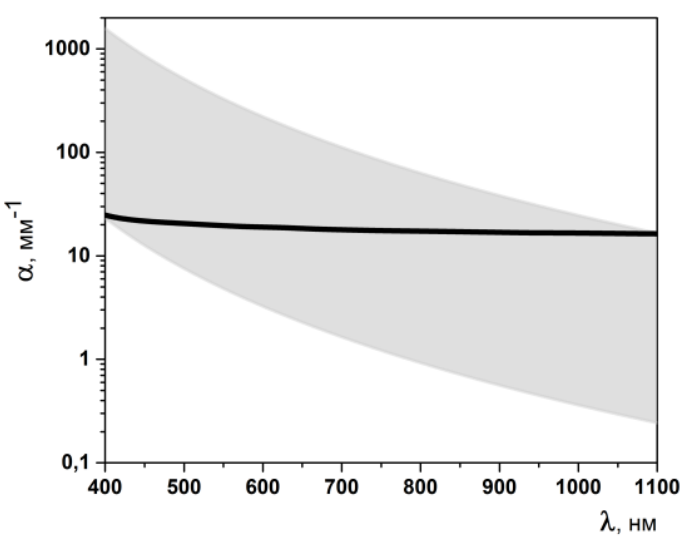

Рис. 4. Зависимость показателя поглощения хрящевой ткани от длины волны

черная линия - экспериментально полученный спектр, заштрихованная область - результат расчета с использованием уравнения (1) 
Отсюда следует, что действие излучения 1 мкм приводит к перфорации биоткани в результате индуцирования неоднородного температурного поля вследствие нерезонансных оптических потерь из-за рассеяния.

\section{ВЫВОдЫ}

По результатам выполненной работы можно сделать следующие выводы. Показана возможность использования лазерного излучения с $\lambda=1,06$ мкм для создания имплантатов на основе хрящевой ткани ушной раковины кролика. Формирование микроструктуры, которую в последующем можно использовать в качестве тканеинженерной конструкции, происходит в результате индуцирования неоднородного температурного поля вследствие нерезонансных оптических потерь из-за рассеяния на компонентах биоткани с масштабом 1-5 мкм.

\section{ЛИТЕРАТ УРА REFERENCES}

1. Baum O. I. et al. The new method for treatment of larynx stenosis based on transplantation of rib cartilage reshaped with $1.56-\mu \mathrm{m}$ laser radiation. Optical Imaging, Therapeutics, and
Advanced Technology in Head and Neck Surgery and Otolaryngology 2019. International Society for Optics and Photonics. 2019. V. 10853. P. 108530G. DOI: 10.1117/12.2511410.

2. Барановский Д. С. и др. Интерлейкин IL-1 $\beta$ стимулирует ревитализацию хрящевого матрикса назальными хондроцитами человека in vitro. Вестник трансплантологии и искусственных органов. 2019. Т. 21. №. 4. C. 88-95. DOI: 10.15825/1995-1191-2019-4-88-95. Baranovskii D.S., Lyundup A.V., Balyasin M.V., Klabukov I.D., Krasilnikova O.A., Krasheninnikov M.E., Parshin V.D. Interleukin IL-1 $\beta$ stimulates cartilage scaffold revitalization in vitro with human nasal chondrocytes. 2019. V. 21. N 4. P. 88-95. DOI: 10.15825/1995-1191-2019-4-88-95 (in Russian).

3. Шахно Е.А. Физические основы применения лазеров в медицине. - СПб: НИУ ИТМО. 2012. 129 с. Shahno E.A. Phyzicheskie osnovy primeneniya lazerov v meditcine. $-\mathrm{SPb}$ : NIU ITMO. 2012. 129 p.

4. Фабелинский И.Л. Молекулярное рассеяние света. М.: Высшая школа. 1965. 512 с. Phabelinsky I.L. Molekulyarnoe rasseyanie sveta. M.: Vysshaya Shkola. 1965. 512 p.

5. Lim E. H., Sardinha J. P., Myers S. Nanotechnology biomimetic cartilage regenerative scaffolds. Archives of plastic surgery. 2014. V. 41. N. 3. P. 231. DOI: 10.5999/aps.2014.41.3.231. 